\title{
MANAGEMENT OF MICRO METASTATIC PAPILLARY CARCINOMA OF THYROID IN SUBMANDIBULAR GLAND
}

\section{Bhanumathi ${ }^{1}$, S. Venkata Ramana ${ }^{2}$}

\section{HOW TO CITE THIS ARTICLE:}

V. Bhanumathi, S. Venkata Ramana. "Management of Micro Metastatic Papillary Carcinoma of Thyroid in Submandibular Gland". Journal of Evolution of Medical and Dental Sciences 2015; Vol. 4, Issue 65, August 13; Page: 11401-11403, DOI: $10.14260 /$ jemds/2015/1644

INTRODUCTION: Micro metastatic papillary carcinoma of thyroid in submandibular gland is rare and most of the time discovered after routine excision of submandibular gland in histopathological examination. ${ }^{1}$ After discovering papillary carcinoma in submandibular gland in the histopathological report, there is a lot of controversy about further management and follow up protocol. Probably the best approach is immediate post-operative ultrasound scan and PET scan of thyroid gland, which may show any evidence of invasion or secondaries. The patient may be further followed up by regular USG and PET scan every six months to detect recurrence so as to avoid unnecessary total thyroidectomy and neck dissection.

Here we report a young female who underwent excisions of submandibular gland. The histopathological examination showed metastatic papillary carcinoma of thyroid in submandibular gland. The patient is managed by above mentioned protocol.

CASE REPORT: A 21 year old female patient came to outpatient department of Gandhi Hospital, Hyderabad, with recurrent submandibular swelling on right side. This swelling was gradually increasing in size with no other symptoms, no previous history of hypothyroidism or hyperthyroidism. A clinical diagnosis of submandibular adenitis was made. Patient was admitted and complete excision of swelling was done and specimen was sent for histopathological examination, which showed Metastatic papillary carcinoma of thyroid in submandibular lymph node. This case is reported as it is rare and to discuss management protocol.

Fig. 1: Lateral view of the patient showing swelling in the suprahyd region extending to right Submandibular area.

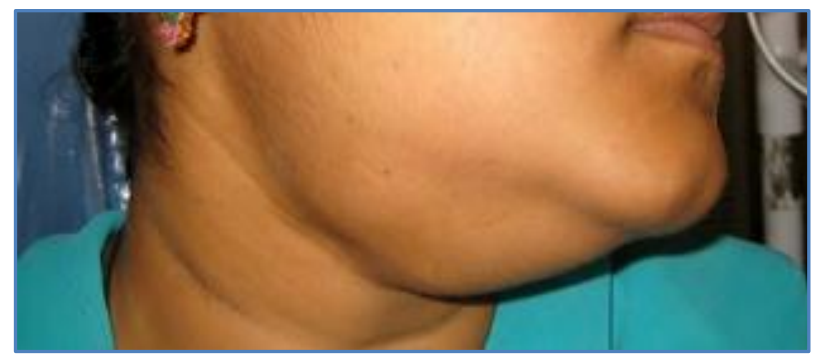

Fig. 1

The following procedures/test has been performed:

- FNAC of swelling done thrice at three different location and result of which were given as: Submandibular adenitis. 
- X-Ray of Mandible-oblique view was taken which showed no Bony lesion.

- Ultrasound of neck concluded it as Submandibular adenitis.

- $\quad$ Thyroid profile was normal.

- Submandibular Gland was completely excised and sent for histopathological examination.

- HPE report followed as metastatic deposit of papillary carcinoma in submandibular gland with occult primary thyroid carcinoma. [Fig. 2].

Fig. 2: Papillary neoplasm arising in submandibular gland which contained entrapped thyroid follicles.

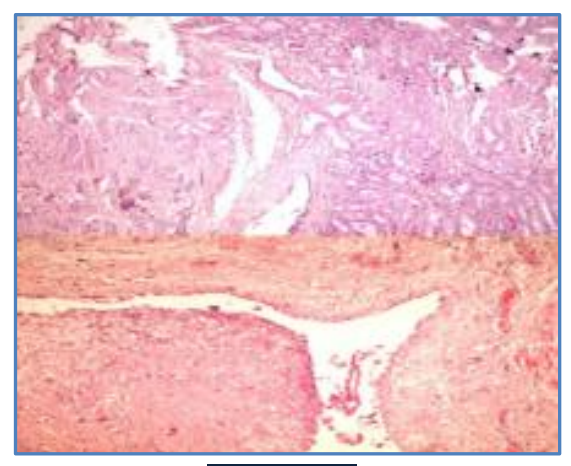

Fig. 2

\section{Immunohistochemistry report shows [Fig. 3]:}

- Tumour cells strongly positive for thyroglobulin, TTF -1, CK- 19.

- Features suggestive of differentiated papillary carcinoma of thyroid.

- Patient was advised USG and technetium scan of thyroid post operatively, below are the observations made:

- USG scan showed no abnormality.

- Technetium scan showed no cold spots.

Fig. 3: Immunohistochemistry /HPC report.
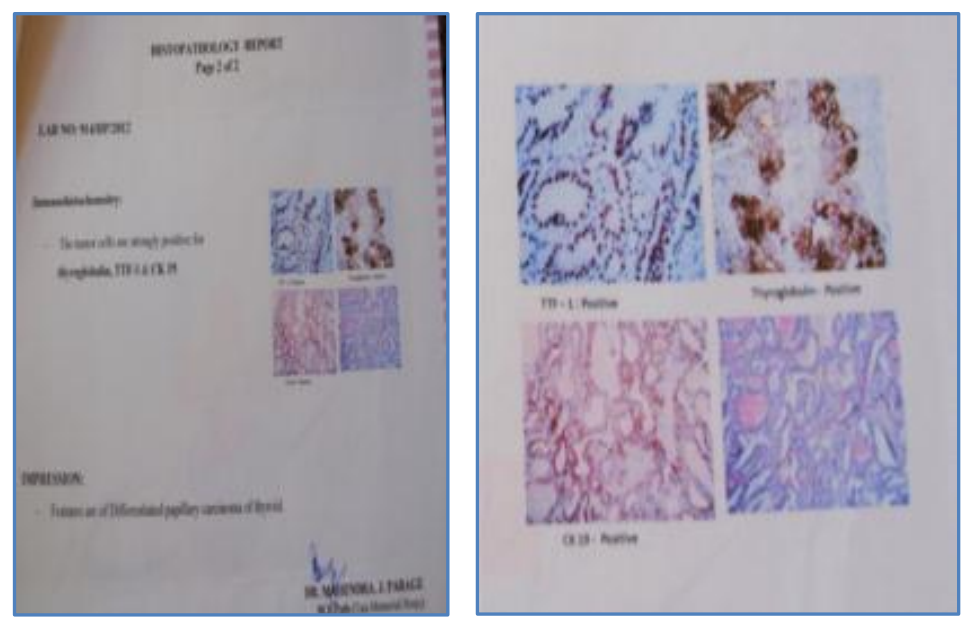

\section{Fig. 3}


No further surgical treatment was undertaken as the patient is reviewed with thyroglobulins levels, technetium scan and USG once in six months and as the patient is young, total thyroidectomy was deferred. Regular follow up showed no abnormality.

DISCUSSION: It has been observed that occult papillary thyroid carcinoma metastasis is rare with normal thyroid gland. Sometimes papillary carcinoma may arise from ectopic thyroid tissue of submandibular gland ${ }^{2}$. This case is presented as a typical histological surprise as micro metastasis of papillary thyroid carcinoma in submandibular gland is rare and never reported previously.

The big question regarding best practice guidelines for further management which still remains controversial and debatable is about the role of total thyroidectomy and regional lymph node dissection in an incidentally discovered papillary carcinoma in submandibular gland with no clinical or radiological evidence of thyroid gland involvement and lymph nodes 3 .

CONCLUSION: Meta static deposits in submandubular gland are rare with diagnosis made upon post op histopathological examination.

The long-term management of these patients is based on their stratification of low, moderate, and high risk groups.

The overall prognosis for papillary carcinoma in submandibular gland is excellent, long term clinical follow up with estimation of regular thyroglobulin levels, Ultrasound scan and pet scan is recommended as papillary cancer is known to have a prolonged clinical course ( $>20$ years).

\section{REFERENCES:}

1. Allo MD, Christianson W, Koivunen D. Not all "occult" papillary carcinomas are "minimal". Surgery 1988; 104: 971-6.

2. Vaidya AM, Vaidya AM, Petruzzelli GJ, McClatchey KD. Isolated submandibular gland metastasis from oral cavity squamous cell

3. Batsakis JG, Bautina E. Metastases to major salivary glands. Ann Otol Rhinol Laryngol 1990; 99: 501-3.

\section{AUTHORS:}

1. V. Bhanumathi

2. S. Venkata Ramana

\section{PARTICULARS OF CONTRIBUTORS:}

1. Associate Professor, Department of Surgery, Osmania Medical College, Hyderabad.

2. Professor, Department of ENT, Government ENT Hospital, Hyderabad.

FINANCIAL OR OTHER COMPETING INTERESTS: None
NAME ADDRESS EMAIL ID OF THE CORRESPONDING AUTHOR:

Dr. V. Bhanumathi, 8-53/2, North Kamala Nagar, ECIL Post, Hyderabad-62.

E-mail: drbahnumathirao@yahoo.com

Date of Submission: 13/07/2015. Date of Peer Review: 24/07/2015. Date of Acceptance: 07/08/2015. Date of Publishing: 13/08/2015. 